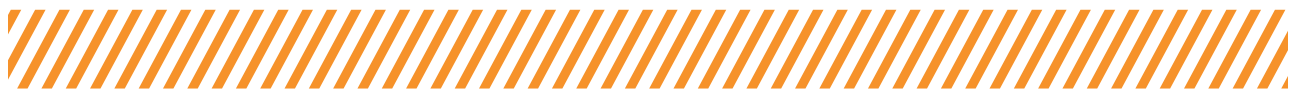

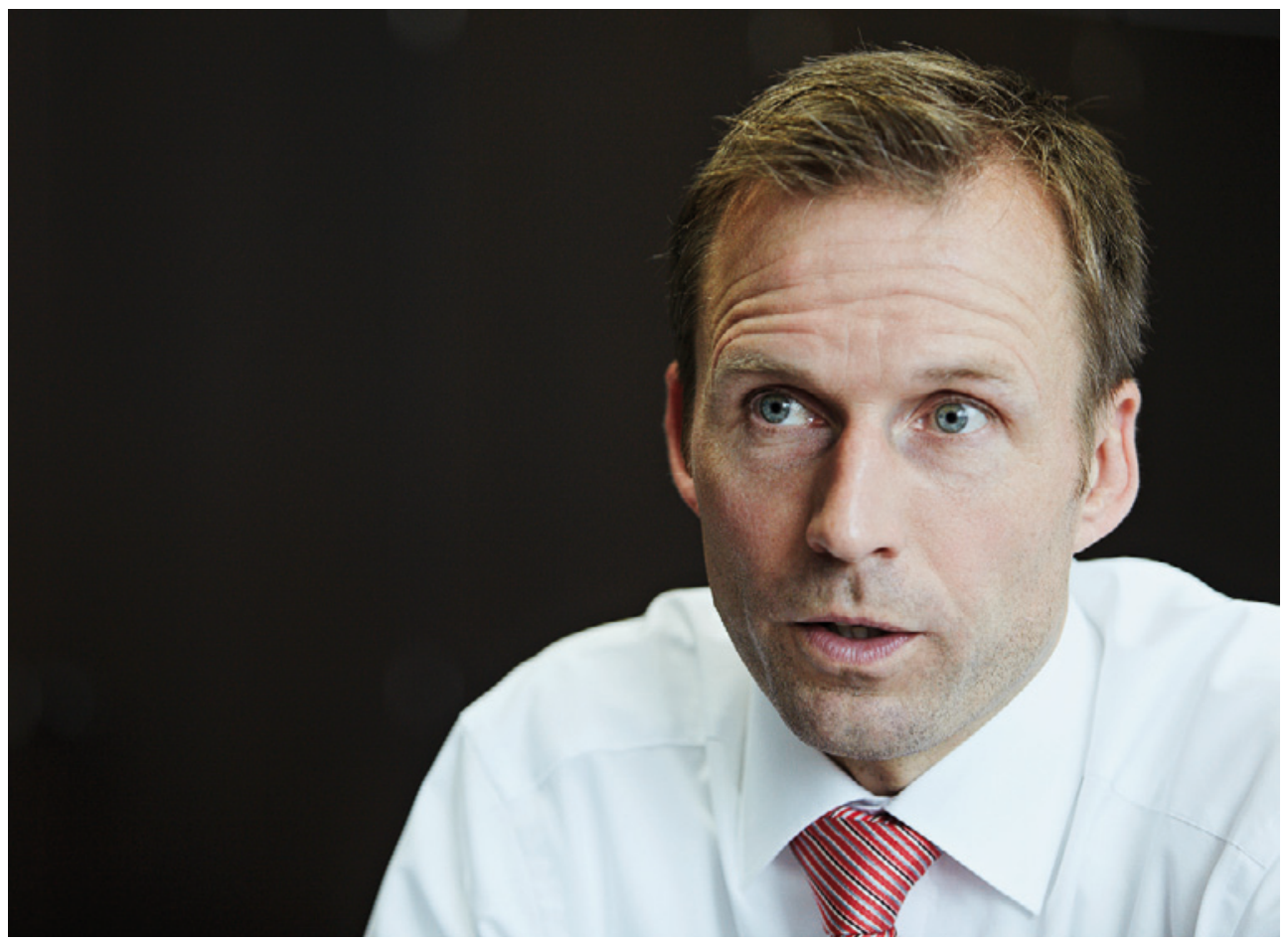

JÖRG GROTENDORST

Leiter der Siemens-Geschäftseinheit Inside eCar in Erlangen

\section{VON DER VERGANGENHEIT LERNEN}

Das Thema Elektromobilität wird sehr häufig im Zusammenhang mit Vereinheitlichung von Komponenten im Antriebsstrang sowie deren Standardisierung diskutiert. Es entsteht zuweilen der Eindruck, der Erfolg der Elektrifizierung hänge allein davon ab, dass man den Elektromotor in Gänze standardisiert - fern ab jeder Emotionalität. Wird für das „erlebbare“ Drehmoment im Auto der Verbrennungsmotor aufwendig kalibriert und beim Elektroantrieb entsteht das Erlebnis hingegen nur aus Einheitsware? Sicher nicht.

Standards sind gut geeignet, um in einem einheitlichen Massenmarkt Kosten zu reduzieren oder bei kleinerem Marktvolumen Applikationsaufwendungen zur Adaption zu reduzieren. Daran arbeiten alle Beteiligten intensiv. Aber ist der Markt der Elektromobilität ausgerechnet für die Kernelemente Motoren, Leistungselektronik und Getriebe überhaupt schon reif dafür? Ich denke: noch nicht.

Alle Autohersteller arbeiten mit Hochdruck daran, höchst effiziente Fahrzeuge und Antriebssysteme für die zukünftigen Emissionsvorschriften zu entwickeln. So unterschiedlich wie die Fahrzeuge werden dabei aber auch die Antriebskonzepte sein. Im Fall von teil- und vollelektrischen Antrieben bestimmt die Traktionsbatterie auf absehbare Zeit die wesentlichen Systemkosten und dabei definiert die Zellchemie und die Anzahl der Zellen in Serie auch die Zwischenkreisspannung. Und die ist entsprechend variantenreich. Jedenfalls im dem noch jungen Markt. Standardisierte Lösungen machen nur dann Sinn, wenn sie eine breite Anwendung, also viele verschiedene Abnehmer finden und damit entsprechende Produktionsvolumina generieren. Solange aber am Beispiel der Leistungselektronik Spannungslage, Leistung und weitere spezielle Anwendungen - wie Hydraulikpumpen, Klimakompressoren, Rotorfremderregungen etc. - mit untergebracht werden müssen, handelt es sich um spezielle, kundenspezifische Lösungen.

Die Einführung neuer technischer Lösungen kommt in der Autoindustrie immer wieder vor. Viele Innovationen wie ABS, ESP, Airbags und Navigation haben es relativ schnell von einer teuren Sonderlösung in eine breite Serienanwendung geschafft - obwohl es zunächst widrige Voraussetzungen ähnlich den zuvor geschilderten für die E-Antriebe gab. Was war der Schlüssel dafür? Eine grundsätzliche Lösung liegt darin, für die jeweilige Fahrzeuganwendung eine optimale Lösung zu finden und dann parallel durch die Lieferanten auf der Komponentenebene modulare Baukästen zu entwickeln. Das schuf nachhaltige Wettbewerbsfähigkeit und ein attraktives Preisniveau.

Warum also verlangt man heute schon nach standardisierten Komponenten, für die es derzeit aber keine Anwendung gibt? Vielleicht muss man bei den Elektroantrieben an die Erfahrungen des ESP anknüpfend lernen, schließlich hat es hier von der ersten Serieneinführung bis zur Darstellung eines Massenmarkts keine 20 Jahre gebraucht. 